\section{Sharing a shrinking budget}

\section{Washington}

LAST week, the US National Academy of Science's Institute of Medicine (IOM) joined the debate over how best to support biomedical research with a 240 -page call for a new balance in science funding*. Based on two years of meetings between some of the top names in biomedical research, the report takes the position that, given constant budgets, more money should be taken from research and put into training and facilities.

The IOM asked its panels to make their recommendations under some sobering assumptions. Three primary scenarios were stipulated: no real growth, 2 per cent real growth, and 4 per cent real growth in biomedical funding. Given these probably realistic constraints (congressional staff say biomedical research funding will be lucky even to keep up with inflation in the about-to-be- completed 1991 budget, despite an annual growth rate of some 10 per cent in numbers of new researchers), the panels chose to shift funding to students and laboratory construction and away from research. Floyd Bloom, chairman of the neuropharmacology department at Scripps Clinic, who led the IOM panel, says the members concluded that the National Institutes of Health (NIH) are "progressively under-funding the things that are necessary to keep the system vital". By funding established researchers at the expense of young investigators, "we're eating our seed corn", he says.

In the first two funding scenarios, the report calls for NIH to increase funding for training from 4.2 to 5.75 per cent of the grant budget by 1995 and to 6.75 per cent by 2000 . Construction funds should also rise from 0.25 to 0.50 per cent of the budget over the next decade, the panels said.

Carol Sheeman, of the Association of American Universities (AAU), says her organization intends to "start beating the drum of this report" in lobbying Congress and NIH for reforms. "This is the clearest look I've seen at the issue of generational equity. It doesn't talk about redoing the whole system; it talks about adapting." Although Bloom says the panels expect a howl of outrage from established researchers, he points out that the proposals represent a total shift of only some $\$ 20$ million a year, or the loss of about 60 research grants out of nearly 5,000 in exchange for 400 new training awards.

Bloom also points out that much of the effect that the IOM panels were seeking can be achieved through private funding, rather than by cutting NIH grants. Indeed, the Howard Hughes Medical Institute (HHMI) is increasing its training budget by more than $\$ 10$ million this year, to over $\$ 65$ million. "We are acutely aware that there is a problem with the pipeline, and we've made a decision to spend at least 20 percent of our funds on training and education", says Purnell Choppin, president of HHMI.

Another controversial aspect of the IOM report is the suggestion that grants be funded not necessarily at the full level requested, but at some level proportional to their relative ranking among other proposals. This "sliding scale" mechanism "takes into consideration the benefits or potential breakthroughs that could be derived from those grant applications falling below arbitrary cut-offs", the report says. For existing grants that face cancellation when they receive a ranking below the cut-off, the report suggests "stepdown" funding, such as 60 per cent for an additional year.

Although many researchers rail at the idea of a cut in their grants, even if it means more for all, the proposals are likely to find a sympathetic ear in Congress. The report language in the current congressional appropriations bills emphasizes the importance of increasing the overall number of grants, at the expense of individual amounts, if need be. Responding to complaints of huge overhead, or "indirect costs", (up to 78 per cent) at many universities, Congress has also asked NIH to stretch the research dollar by favouring those with lower costs.

But NIH officials are concerned that such a move could hurt universities that are simply placed in an expensive part of the country. The consideration of indirect costs "would favour middle America schools over those on the East and West coast", says John Diggs, NIH extramural research director. AAU's Sheeman points out that schools in temperate climates would also be favoured because they spend less on heating and air-conditioning, two substantial portions of a institution's calculated overhead.

Nevertheless, NIH officials recognize that reforms, even drastic reforms, are inevitable as the number of researchers grows faster than the budget. "We have our work cut out for us", says Diggs. A series of NIH advisory panels are expected to finish their recommendations on the congressional proposals this month, and NIH is considering the IOM report as well. Given that every day without a 1991 budget (the fiscal year began this week with Congress still debating an agreement) means less money for all, NIH may be forced to impose some of the changes within months.

\section{Christopher Anderson}

*Funding Health Sciences Research - A Strategy To Restore Balance; National Academy Press. November, 1990.

\section{Frontiers open up}

\section{Paris}

THE Commission of the European Communities (CEC) has finally decided that the European Communities will take part in the Human Frontier Science Program (HFSP) for what is left of the programme's trial period (until March 1992). The decision follows a proposal put forward by CEC vice-president Filippo Maria Pandolfi and will allow participation of several European countries that have so far not had full access to the programme.

HFSP grew out of plans first put forward officially by the Japanese government at the 1987 Venice economic summit of the group of seven (G7) leading industrial nations. For a three-year trial period, Japan is putting up the lion's share ( $¥ 2,384$ million for the first year) of funding for an international, interdisciplinary basic research programme into higher brain functions and biological functions at the molecular level. The programme has given scientists from the G7 founder-member countries access to a new and attractive source of funding.

Janet Watford, responsible for HFSP within the CEC, explains that Japan also invited the European Communities to take part, as they are also represented at G7 summits. But official procedures have meant that, until the recent CEC decision, European member states (apart from Britain, France, Italy and West Germany) have not been able to participate fully in HFSP. Now, says Watford, smaller members of the European Communities will be able to take part on the same basis as the founder members and can be principal researchers on joint projects.

CEC will now provide bursaries and organize workshops for HFSP research, but no new money will be available. Instead, existing funds ear-marked for CEC research programmes will be made available for applications under HFSP's terms of reference. P.C. HIGH-ENERGY PHYSICS A proton shared...

\section{London}

Muon research is to be the latest beneficiary of Japanese research spending in the United Kingdom. The Japanese Institute of Physical and Chemical Research (RIKEN) will spend $£ 6$ million to set up a complex of muon beamlines on Isis, the spallation neutron source at the Science and Engineering Research Council's Rutherford Appleton Laboratory. Researchers from Japan and Britain will use the new facility, studying muon-catalysed nuclear fusion and measuring magnetic fields at the atomic level. RIKEN will save money through the collaborative arrangement, dispensing with the need to build a source of high-energy protons (which Isis produces) to generate muons.

P.A. 